\title{
Phase Ib Trial of the PI3K Inhibitor Copanlisib Combined with the Allosteric MEK Inhibitor Refametinib in Patients with Advanced Cancer
}

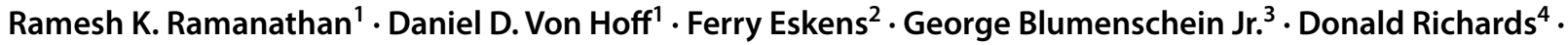 \\ Isabelle Genvresse ${ }^{5} \cdot$ Susanne Reschke ${ }^{5} \cdot$ Camille Granvil $^{6} \cdot$ Adam Skubala $^{7} \cdot$ Carol Peña $^{6} \cdot$ Klaus Mross $^{8}$
}

Published online: 20 April 2020

(c) The Author(s) 2020, corrected publication 2020

\begin{abstract}
Background Dual inhibition of PI3K and MAPK signaling is conceptually a promising anticancer therapy.

Objective This phase $1 \mathrm{~b}$ trial investigated the safety, maximum tolerated dose (MTD), recommended phase II dose, pharmacokinetics, tumor response, fluorodeoxyglucose positron emission tomography (FDG-PET) pharmacodynamics, and biomarker explorations for the combination of pan-PI3K inhibitor copanlisib and allosteric MEK inhibitor refametinib in patients with advanced solid tumors.

Patients and methods This was an adaptive trial with eight dose cohorts combining dose escalation and varying schedules in repeated 28 -day cycles. Patients received copanlisib $(0.2-0.8 \mathrm{mg} / \mathrm{kg}$ intravenously) intermittently (days $1,8,15)$ or weekly (days $1,8,15,22)$ each cycle, and refametinib (30-50 mg twice daily orally) continuously or 4 days on/3 days off. Patients with KRAS, NRAS, BRAF, or PI3KCA mutations were eligible for the expansion cohort.

Results In the dose-escalation $(n=49)$ and expansion $(n=15)$ cohorts, the most common treatment-emergent adverse events included diarrhea (59.4\%), nausea, acneiform rash, and fatigue (51.6\% each). Dose-limiting toxicities included oral mucositis $(n=4)$, increased alanine aminotransferase/aspartate aminotransferase $(n=3)$, acneiform rash, hypertension $(n=2$ each), and diarrhea $(n=1)$. MTD was copanlisib $0.4 \mathrm{mg} / \mathrm{kg}$ weekly and refametinib $30 \mathrm{mg}$ twice daily. No pharmacokinetic interactions were identified. Decreased tumor FDG uptake and MEK-ERK signaling inhibition were demonstrated during treatment. Best response was stable disease $(n=21)$; median treatment duration was 6 weeks.

Conclusions Despite sound rationale and demonstrable pharmacodynamic tumor activity in relevant tumor populations, a dose and schedule could not be identified for this drug combination that were both tolerable and offered clear efficacy in the population assessed.
\end{abstract}

Clinicaltrials.gov identifier NCT01392521.

\section{Introduction}

Aberrant activation of phosphatidylinositol 3-kinase (PI3K)/ AKT/mammalian target of rapamycin (mTOR) and RAS/ RAF/MAPK signaling is frequently implicated in tumorigenesis. These signaling pathways are interconnected,

Electronic supplementary material The online version of this article (https://doi.org/10.1007/s11523-020-00714-0) contains supplementary material, which is available to authorized users.

Daniel D. Von Hoff

dvh@tgen.org

Extended author information available on the last page of the article allowing for compensatory signal transduction when one pathway is inhibited [1,2]. Dual inhibition of these pathways in vitro and in vivo has demonstrated synergistic tumor stasis and antitumor efficacy [3, 4]; hence, combination therapy may provide improved clinical outcomes in cancer patients.

Copanlisib (Bayer AG, Berlin, Germany) is an intravenous, pan-class I PI3K inhibitor with predominant activity against PI3K- $\alpha$ and PI3K- $\delta$ isoforms [5, 6]. In a first-inhuman study, copanlisib demonstrated antitumor activity in patients with solid tumors; the maximum tolerated dose (MTD) was $0.8 \mathrm{mg} / \mathrm{kg}$ (equivalent to a 60-mg fixed dose) [7]. In a recent phase II study, copanlisib $60 \mathrm{mg}$ demonstrated significant efficacy and manageable toxicity in heavily pretreated patients with indolent lymphoma [8]. Based on these 


\section{Key Points}

Inhibition of two separate yet interconnected oncogenic signaling pathways (PI3K and MEK) is a promising approach for anticancer therapy, to avoid compensatory signaling if only one pathway alone was inhibited.

In this phase Ib study, the combination of the panPI3K inhibitor copanlisib plus allosteric MEK inhibitor refametinib was tolerated only at a sub-clinically active dose in patients with advanced solid tumors, and optimal dosing for PI3K-MEK inhibitor combination regimens remains to be established.

results, copanlisib was approved by the US Food and Drug Administration for the treatment of patients with relapsed follicular lymphoma [9]. Refametinib (BAY 86-9766; Bayer AG, Berlin, Germany) is a highly selective, orally administered allosteric MEK1/2 inhibitor [10] that demonstrated good tolerability and clinical activity in a phase I study; the MTD was $50 \mathrm{mg}$ twice daily (BID) [11]. Copanlisib combined with refametinib has demonstrated synergy, with observed tumor stasis in colorectal cancer (CRC) tumor cell lines (with wild-type or mutant KRAS) [12], non-smallcell lung cancer (NSCLC) cell lines [13] and biliary tract cancer models [14] with various genetic alterations; tumor progression was observed with either agent alone. These data supported further study of the combination, especially in patients with metastatic KRAS-mutant CRC and NSCLC (with wild-type or mutant EGFR).

Previous combination studies using oral PI3K and MEK inhibitors have demonstrated antitumor activity, although long-term tolerability is challenging due to frequent dose interruptions and reductions, often due to gastrointestinal toxicities $[15,16]$. Intravenous copanlisib, administered intermittently, has demonstrated manageable safety and is potentially advantageous compared with oral PI3K inhibitors, with low incidences of fatal hepatic and/or gastrointestinal toxicity [8], supporting the rationale for the study of intravenous copanlisib combined with oral refametinib.

The primary objectives of this phase Ib study were to determine the safety, tolerability, MTD, and recommended phase II doses (RP2D) of intravenous copanlisib combined with oral refametinib in patients with advanced cancer, and to determine any possible pharmacokinetic interaction. Secondary objectives were to assess antitumor activity and to explore potentially predictive and pharmacodynamic biomarkers.

\section{Patients and Methods}

\subsection{Study Design and Treatments}

This was a multicenter, open-label, non-randomized, doseescalation study comprising a dose-escalation scheme plus an expansion cohort (NCT01392521). Dose escalation followed an adaptive design in repeated 28-day cycles (Supplementary Fig. S1). Copanlisib dosing started at $0.2 \mathrm{mg} / \mathrm{kg}$ ( $25 \%$ of the single-agent MTD [7]) administered intravenously over $1 \mathrm{~h}$, intermittently on days 1,8 , and 15 of each cycle [7,8], or in later cohorts on days $1,8,15$, and 22 of each cycle, and was to be escalated to the MTD of $0.8 \mathrm{mg} / \mathrm{kg}$, with a maximum dose of $65 \mathrm{mg}$. Refametinib dosing started at $30 \mathrm{mg}$ BID ( $60 \%$ of the single-agent MTD) administered continuously from cycle 1 , day 4 , or in later cohorts intermittently for 4 days on/ 3 days off starting on cycle 1 , day 6 , and was to be escalated to the MTD of $50 \mathrm{mg}$ BID [11].

If $\leq 1 / 6$ patients in a cohort experienced a dose-limiting toxicity (DLT) in the first cycle, escalation to the next dose level would commence. If $\geq 2 / 6$ patients experienced a DLT, the MTD would have been exceeded and dose escalation would cease. Criteria for DLTs are provided in the Online Supplementary Material. Following tolerability assessment of cohorts $2 \mathrm{~A}, 2 \mathrm{~B}$, and $2 \mathrm{C}$, and review of the data from all dose levels tested by the investigators, the highest tolerable combination was selected for $\geq 12$ additional patients enrolled into an expansion cohort for further safety, preliminary efficacy, and biomarker evaluations (Supplementary Fig. S1).

The study was compliant with the Declaration of Helsinki and Good Clinical Practice, and was approved by the appropriate ethics committees. All patients provided written, informed consent.

\subsection{Inclusion Criteria}

Patients aged $\geq 18$ years with histologically or cytologically confirmed incurable and refractory advanced solid tumors were eligible. Patients must have had $\geq 1$ measurable lesion or evaluable disease according to Response Evaluation Criteria in Solid Tumors version 1.1 (RECIST), life expectancy of $\geq 12$ weeks, and an Eastern Cooperative Oncology Group performance status of $\leq 1$. Enrollment into the expansion cohort required the presence of an activating tumor mutation in KRAS, NRAS, BRAF, and/or PI3KCA. Patients could be enrolled into the expansion cohort with mutation data based on either historical results (any tumor mutation result generated before enrollment into the trial) or prospectively generated central laboratory mutation analysis 
of circulating tumor DNA isolated from plasma collected during screening.

\subsection{Assessments}

Tumors were measured by computed tomography or magnetic resonance imaging at screening, within 7 days of the start of each odd-numbered cycle, and within 30 days of the last dose. Tumor response was assessed using RECIST. Ophthalmologic examinations were performed at screening and day 1 ( \pm 7 days) of every third cycle. Safety, pharmacokinetic, pharmacodynamic, and biomarker assessments are detailed in the Online Supplementary Material.

\subsection{Statistical Analysis}

Statistical analyses are detailed in the Online Supplementary Material.

\section{Results}

\subsection{Patients and Treatment}

Eighty-seven patients were screened and 64 were assigned to copanlisib and refametinib treatment: 49 in dose-escalation cohorts and 15 in the expansion cohort (Supplementary Fig. S1). The mean age was 58.4 years; 38 patients $(59.4 \%$ ) had received $\geq 3$ prior regimens. Common cancer types included CRC (34.4\%) and NSCLC (14.1\%) (Table 1).

Patients received a median of two copanlisib cycles (range 1-6) and two refametinib cycles (range 1-7). Patients received a median of six copanlisib infusions (range 1-22) and a median daily dose of refametinib $58.7 \mathrm{mg}$ (range 20-100). Median duration of treatment for copanlisib and refametinib was 6.1 weeks (range 0.1-28.0) and 6.9 weeks (range 0.6-28.0), respectively.

\subsection{Dose Escalation and Dose-Limiting Toxicities}

Sixteen patients (25.0\%) had DLTs, including oral mucositis and increased alanine aminotransferase/aspartate aminotransferase (Table 2). Dose 3A was considered intolerable because of a DLT in one patient and multiple adverse events (AEs) leading to dose reduction or dropout. Doses 3B and $3 \mathrm{BN}$ were considered intolerable because $4 / 6$ and $2 / 6$ patients, respectively, had DLTs during cycle 1 . No patients were enrolled to planned cohorts $3 \mathrm{AN}, 4$, or $4 \mathrm{~N}$. DLTs were observed in $1 / 4,2 / 4$, and $1 / 7$ patients, respectively, in cohorts $2 \mathrm{~A}, 2 \mathrm{~B}$, and $2 \mathrm{C}$. Therefore, the MTD for the combination was established as copanlisib $0.4 \mathrm{mg} / \mathrm{kg}$ once weekly plus refametinib $30 \mathrm{mg}$ BID (dose 2C). Of the 15 patients treated at the MTD in the expansion cohort, two presented with AEs that met protocol-defined DLT criteria (Table 2).

\subsection{Safety and Tolerability}

At least one treatment-emergent AE (TEAE) was observed in all patients; TEAEs considered related to copanlisib or refametinib were reported in $60(93.8 \%)$ and 61 (95.3\%) patients, respectively. The most common TEAEs of any grade (in $>50 \%$ of patients) were diarrhea, nausea, acneiform rash, and fatigue (Table 3 ). Eight patients (12.5\%) experienced $\geq 1$ treatment-emergent eye disorder of any grade: blurred vision $(n=4[6.3 \%])$, other disorders $(n=2[3.1 \%]$; optic hemorrhage and conjunctival pallor), conjunctivitis, dry eye, and keratitis ( $n=1$ each [1.6\%]). Eye disorders were grade 1 in six patients and grade 2 or 3 in one patient each (one patient had grade 3 optic disc hemorrhage which recovered). TEAEs of worst grade 3 or 4 were reported in $68.8 \%(n=44)$ and $10.9 \%(n=7)$ of patients, respectively. The most common grade 3 TEAEs (in $\geq 5$ patients) were hypertension (26.6\%; $n=17)$, diarrhea $(10.9 \% ; n=7)$, anemia, hyponatremia, maculopapular rash ( $9.4 \%$ each; $n=6$ ), acneiform rash, dyspnea, and oral mucositis (7.8\% each; $n=5)$. The most common grade 4 TEAE was increased creatine phosphokinase (3.1\% [all-grade, 15.6\%]).

Twelve patients (18.8\%) experienced $\geq 1$ serious TEAE related to either copanlisib or refametinib, most commonly worst grade 3 (Table 4). All drug-related serious TEAEs were considered related to the combination therapy, except for one case of grade 1 pneumonitis (copanlisib only) and one case each of grade 3 acneiform rash and grade 3 diarrhea (refametinib only).

Dose modifications (interruptions, delays, or reductions) occurred in 45 patients $(70.3 \%)$ and were attributed to copanlisib-related TEAEs in 25 patients (39.1\%) and refametinib-related TEAEs in 34 patients (53.1\%). Twentyone patients (32.8\%) had TEAEs leading to permanent discontinuation, including 6/22 patients (27.3\%) treated at the MTD. Most events leading to treatment discontinuation were grade $3(23.4 \% ; n=15)$, most commonly oral mucositis and maculopapular rash (3.1\% each; $n=2)$; grade 4 events were reported in two patients (ileus and respiratory failure, $n=1$ each).

Nine deaths were reported within 30 days after treatment discontinuation, including one deemed copanlisib-related following grade 2 renal insufficiency and dehydration (assessed as a DLT).

\subsection{Pharmacokinetics}

Single-agent pharmacokinetics were measured on days 1 and 14 for copanlisib and refametinib, respectively, and in 


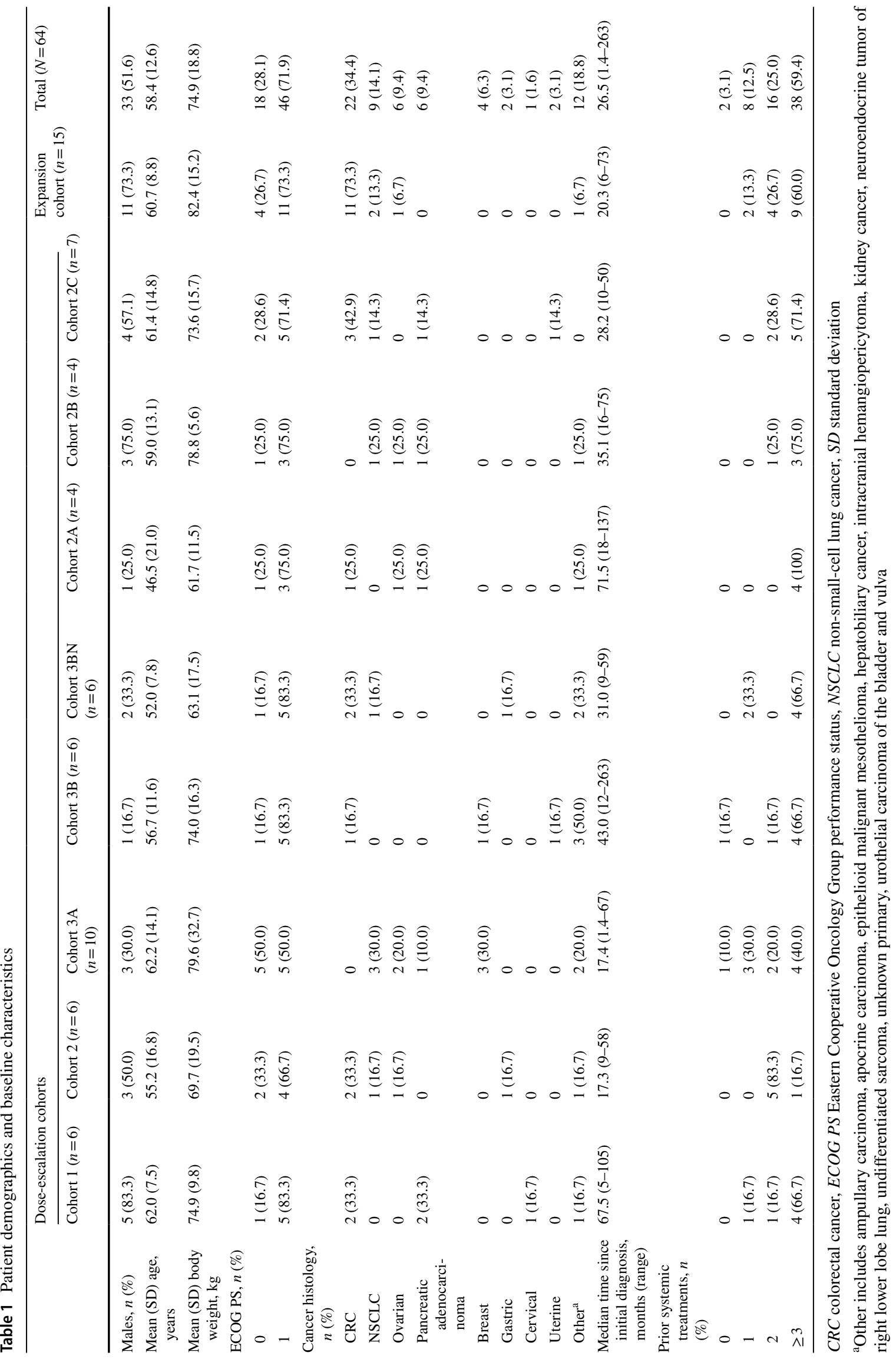


Table 2 Overview of dose-limiting toxicities and relationship to study drug

\begin{tabular}{|c|c|c|c|c|}
\hline Cohort & Copanlisib dose & Refametinib dose & $\begin{array}{l}\text { Patients with } \\
\text { DLT(s)/treated } \\
\text { patients }\end{array}$ & DLT $^{\mathrm{a}}$ \\
\hline 1 & $0.2 \mathrm{mg} / \mathrm{kg} 3$ weeks on $/ 1$ week off & $30 \mathrm{mg}$ BID & $1 / 6$ & Grade 3 pancreatitis \\
\hline $3 \mathrm{~A}$ & $0.8 \mathrm{mg} / \mathrm{kg} 3$ weeks on $/ 1$ week off & $30 \mathrm{mg}$ BID & $1 / 10$ & Grade 3 diarrhea \\
\hline $3 B$ & $0.4 \mathrm{mg} / \mathrm{kg} 3$ weeks on $/ 1$ week off & $50 \mathrm{mg}$ BID & $6 / 6$ & $\begin{array}{l}\text { Grade } 3 \text { acneiform rash, grade } 3 \text { oral mucositis, grade } 3 \\
\text { dehydration, grade } 3 \text { dry skin, grade } 4 \text { hypernatremia, } \\
\text { grade } 3 \text { increased AST, grade } 3 \text { hypertension, grade } \\
3 \text { fatigue }\end{array}$ \\
\hline $3 \mathrm{BN}$ & $0.4 \mathrm{mg} / \mathrm{kg}$ weekly & $50 \mathrm{mg}$ BID & $2 / 6$ & Grade 3 increased ALT, grade 3 increased ALT \\
\hline $2 \mathrm{~A}$ & $0.6 \mathrm{mg} / \mathrm{kg}$ weekly & $30 \mathrm{mg}$ BID & $1 / 4$ & Grade 3 hypertension \\
\hline $2 \mathrm{~B}$ & $0.6 \mathrm{mg} / \mathrm{kg} 3$ weeks on $/ 1$ week off & $30 \mathrm{mg}$ BID & $2 / 4$ & Grade 3 oral mucositis, grade 3 hypertension \\
\hline $2 \mathrm{C}$ & $0.4 \mathrm{mg} / \mathrm{kg}$ weekly & $30 \mathrm{mg}$ BID & $1 / 7$ & Grade 3 oral mucositis \\
\hline Expansion & $0.4 \mathrm{mg} / \mathrm{kg}$ weekly & $30 \mathrm{mg}$ BID & $2 / 15$ & Grade 3 acneiform rash, grade 3 oral mucositis \\
\hline
\end{tabular}

$A L T$ alanine aminotransferase, $A S T$ aspartate aminotransferase, $B I D$ twice daily, $D L T$ dose-limiting toxicity

${ }^{a}$ DLTs assessed using National Cancer Institute Common Terminology Criteria for Adverse Events version 4.0; patients may have more than one DLT

${ }^{\mathrm{b}}$ Grade 3 fatigue started during treatment cycle 2 in two patients

Table 3 Summary of treatment-emergent adverse events ${ }^{\mathrm{a}}$

\begin{tabular}{|c|c|c|c|}
\hline$n(\%)$ & & & Total $(N=64)$ \\
\hline Any TEAE & & & $64(100)$ \\
\hline Grade 1 & & & 0 \\
\hline Grade 2 & & & $5(7.8)$ \\
\hline Grade 3 & & & $44(68.8)$ \\
\hline Grade 4 & & & $7(10.9)$ \\
\hline Grade 5 & & & $9(14.1)$ \\
\hline TEAEs occurring in $\geq 20 \%$ of patients & All-grade & Grade 3 & Grade 4 \\
\hline Diarrhea & $38(59.4)$ & $7(10.9)$ & 0 \\
\hline Acneiform rash & $33(51.6)$ & $5(7.8)$ & 0 \\
\hline Fatigue & $33(51.6)$ & $4(6.3)$ & 0 \\
\hline Nausea & $33(51.6)$ & 0 & 0 \\
\hline Vomiting & $27(42.2)$ & $2(3.1)$ & 0 \\
\hline Hyperglycemia & $26(40.6)$ & $2(3.1)$ & 0 \\
\hline Hypertension & $25(39.1)$ & $17(26.6)$ & 0 \\
\hline Maculopapular rash & $24(37.5)$ & $6(9.4)$ & 0 \\
\hline Oral mucositis & $24(37.5)$ & $5(7.8)$ & 0 \\
\hline Limb edema & $21(32.8)$ & 0 & 0 \\
\hline Anorexia & $20(31.3)$ & $2(3.1)$ & 0 \\
\hline Abdominal pain & $19(29.7)$ & $3(4.7)$ & 0 \\
\hline Dyspnea & $17(26.6)$ & $5(7.8)$ & 0 \\
\hline Pruritus & $17(26.6)$ & 0 & 0 \\
\hline Constipation & $15(23.4)$ & 0 & 0 \\
\hline Fever & $15(23.4)$ & $2(3.1)$ & 0 \\
\hline Investigations - other, specify & $15(23.4)$ & $2(3.1)$ & 0 \\
\hline Hypokalemia & $14(21.9)$ & $2(3.1)$ & $1(1.6)$ \\
\hline
\end{tabular}

TEAE treatment-emergent adverse event

${ }^{\mathrm{a}}$ Adverse events classified and graded using National Cancer Institute Common Terminology Criteria for Adverse Events version 4.0 
Table 4 Serious treatment-emergent adverse events of grade $\geq 3$ considered related to copanlisib or refametinib

\begin{tabular}{ll}
\hline$n(\%)$ & Total $(N=64)$ \\
\hline Patients with $\geq 1$ TEAE & \\
Grade 3 & $4(6.3)^{\mathrm{b}}$ \\
Diarrhea & $2(3.1)$ \\
Hyperglycemia & $1(1.6)$ \\
Abdominal pain & $1(1.6)^{\mathrm{b}}$ \\
Acneiform rash & $1(1.6)$ \\
Anemia & $1(1.6)$ \\
Dehydration & $1(1.6)$ \\
Fatigue & $1(1.6)$ \\
Lung infection & $1(1.6)$ \\
Pancreatitis & $1(1.6)$ \\
Pleural effusion & $1(1.6)$ \\
Syncope & $1(1.6)$ \\
Vomiting & \\
Grade 4 & $1(1.6)$ \\
Increased creatine phosphokinase & \\
Grade 5 & $1(1.6)$ \\
Death—not otherwise specified & \\
\hline
\end{tabular}

TEAE treatment-emergent adverse event

${ }^{a}$ Adverse events classified and graded using National Cancer Institute Common Terminology Criteria for Adverse Events version 4.0

${ }^{b}$ Includes one serious TEAE related to refametinib only

${ }^{c}$ Death following grade 2 renal insufficiency assessed as drug-related and grade 3 dehydration assessed as dose-limiting toxicity

combination on day 15 . Following a single copanlisib infusion at doses of $0.2-0.8 \mathrm{mg} / \mathrm{kg}$ (cycle 1 , day 1 ), the geometric mean maximum drug concentration $\left(C_{\max }\right)$ reached $118-403 \mu \mathrm{g} / \mathrm{L}$ at a median time of $0.50-1.03 \mathrm{~h}$, with coefficients of variation (CVs) of 16.6-146\% (Table 5). The area under the curve from time 0 to $25 \mathrm{~h}$ after the start of infusion ( $\mathrm{AUC}_{(0-25)}$ ) from $0.2-0.8 \mathrm{mg} / \mathrm{kg}$ ranged from 305-1,210 $\mu \mathrm{g} \cdot \mathrm{h} / \mathrm{L}$, with CVs of $16.0-63.1 \%$. Within each cohort, copanlisib $C_{\max }$ and $\mathrm{AUC}_{(0-25)}$ were comparable between day 1 and day 15 .

Following multiple doses of refametinib $30 \mathrm{mg}$ or $50 \mathrm{mg}$ BID, geometric mean $C_{\max }$ reached $484-1,220 \mu \mathrm{g} / \mathrm{L}$ at a median time of $1.50-4.00 \mathrm{~h}$, with CVs of $20.6-101 \%$ (Table 6). AUC from time 0 to $8 \mathrm{~h}\left(\mathrm{AUC}_{(0-8)}\right)$ ranged from $2,510-5,310 \mu \mathrm{g} \cdot \mathrm{h} / \mathrm{L}$, with CVs of $20.5-126 \% . C_{\max }$ and $\mathrm{AUC}_{(0-8)}$ were slightly lower with refametinib monotherapy versus concomitant copanlisib.

\subsection{Clinical and Pharmacodynamic Activity}

No complete or partial responses were observed. Seven patients $(10.9 \%)$ had stable disease lasting $2-4$ cycles as best response. Thirty-one patients $(48.4 \%)$ had progressive disease, one (1.6\%) had non-complete response/non-progressive disease (defined as the response in one non-target lesion due to no measureable target lesion at baseline), and $11(17.2 \%)$ were not evaluable (Fig. 1). Of 51 patients for whom tumor shrinkage values by investigator assessment were available, modest improvements in the best change in target lesion size from baseline were observed (Fig. 2). In cohort 2C, 4/7 patients (57.1\%) had tumor shrinkage and stable disease as best response, contributing to the decision to use this dose in the expansion cohort. In the expansion cohort in patients treated at the MTD, 5/15 patients (33.3\%) had stable disease as best response, with three patients having some degree of tumor shrinkage (Fig. 2).

\subsubsection{Fluorodeoxyglucose Positron Emission Tomography (FDG-PET) Tumor Response}

Paired FDG-PET scans were evaluable in 23/30 patients from cohorts $2 \mathrm{~A}, 2 \mathrm{~B}, 2 \mathrm{C}$, and the expansion cohort

Table 5 Copanlisib geometric mean (\% coefficient of variation) pharmacokinetic parameters on cycle 1, day 1 (copanlisib alone) and day 15 (copanlisib and refametinib)

\begin{tabular}{|c|c|c|c|c|}
\hline \multirow{2}{*}{$\begin{array}{l}{[n]} \\
\text { Cohort } \\
\end{array}$} & \multicolumn{2}{|l|}{ Day 1} & \multicolumn{2}{|l|}{ Day 15} \\
\hline & $C_{\max }(\mu \mathrm{g} / \mathrm{L})$ & $\mathrm{AUC}_{(0-25)}(\mu \mathrm{g} \cdot \mathrm{h} / \mathrm{L})$ & $C_{\max }(\mu \mathrm{g} / \mathrm{L})$ & $\operatorname{AUC}_{(0-25)}(\mu \mathrm{g} \cdot \mathrm{h} / \mathrm{L})$ \\
\hline 1 & $126(146)[6]$ & $305(57.3)[5]$ & 123 (168) [6] & $362(135)[4]$ \\
\hline 2 & 189 (84.9) [6] & $564(16.0)[5]$ & 185 (10.9) [6] & $632(35.0)[6]$ \\
\hline $3 \mathrm{~A}$ & $353(65.8)[10]$ & 1080 (49.6) [10] & $319(84.5)[5]$ & 1090 (49.7) [5] \\
\hline $3 B$ & 247 (29.9) [6] & 693 (49.6) [6] & $246(14.4)[4]$ & $956(45.0)[3]$ \\
\hline $3 \mathrm{BN}$ & 118 (16.6) [6] & $432(44.9)[6]$ & $154(38.9)[5]$ & $482(34.1)[5]$ \\
\hline $2 \mathrm{~A}$ & $403(72.5)[3]$ & $1210(24.9)[3]$ & 194 (88.6) [3] & 619 (123) [3] \\
\hline $2 \mathrm{~B}$ & $212(44.1)[3]$ & $947(32.9)[3]$ & $371(148)[4]$ & 1250 (76.4) [4] \\
\hline $2 \mathrm{C}$ & 241 (104) [7] & 725 (45.5) [7] & 303 (84.6) [6] & 743 (37.5) [6] \\
\hline Expansion & $312(111)[15]$ & $890(63.1)$ [15] & 257 (108) [14] & 770 (33.8) [14] \\
\hline
\end{tabular}

$A U C_{(0-25)}$ area under the curve from time 0 to $25 \mathrm{~h}$ after the start of infusion, $C_{\max }$ maximum drug concentration 
Table 6 Refametinib geometric mean (\% coefficient of variation) pharmacokinetic parameters on cycle 1, day 14 (refametinib alone) and day 15 (refametinib and copanlisib)

\begin{tabular}{|c|c|c|c|c|}
\hline \multirow{2}{*}{$\begin{array}{l}{[n]} \\
\text { Cohort }\end{array}$} & \multicolumn{2}{|l|}{ Day 14} & \multicolumn{2}{|l|}{ Day 15} \\
\hline & $C_{\max }(\mu \mathrm{g} / \mathrm{L})$ & $\mathrm{AUC}_{(0-8)}(\mu \mathrm{g} \cdot \mathrm{h} / \mathrm{L})$ & $C_{\max }(\mu \mathrm{g} / \mathrm{L})$ & $\operatorname{AUC}_{(0-8)}(\mu \mathrm{g} \cdot \mathrm{h} / \mathrm{L})$ \\
\hline 1 & 484 (101) [6] & 2510 (126) [6] & 433 (77.9) [6] & 2240 (101) [6] \\
\hline 2 & $943(52.3)[6]$ & $5110(55.3)[6]$ & 795 (47.2) [6] & 4920 (46.7) [6] \\
\hline $3 \mathrm{~A}$ & $822(55.3)[8]$ & $4530(44.3)[8]$ & $625(34.3)[7]$ & 3790 (36.4) [7] \\
\hline 3B & $1220(80.0)[3]$ & 4910 (98.4) [3] & $672(102)[4]$ & 4130 (118) [4] \\
\hline $3 \mathrm{BN}$ & $--^{\mathrm{a}}$ & $--^{\mathrm{a}}$ & 1080 (39.7) [5] & $6170(48.5)[5]$ \\
\hline $2 \mathrm{~A}$ & $743(24.2)[3]$ & $3300(47.7)[3]$ & $452(60.2)[3]$ & $2560(65.0)[3]$ \\
\hline $2 \mathrm{~B}$ & $607(32.1)[3]$ & $3750(21.1)[3]$ & $631(31.8)[3]$ & 3810 (29.9) [3] \\
\hline $2 \mathrm{C}$ & 873 (38.1) [6] & 4770 (48.3) [6] & $766(46.4)[6]$ & $3900(50.6)[5]$ \\
\hline Expansion & 845 (20.6) [14] & $5310(20.5)[14]$ & 691 (34.7) [15] & 4420 (31.6) [15] \\
\hline
\end{tabular}

$A U C_{(0-8)}$ area under the curve from time 0 to $8 \mathrm{~h}$ after the start of infusion, $C_{\max }$ maximum drug concentration

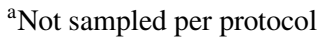

(including 16 treated at the MTD in cohort 2C and the expansion cohort). Eighteen patients (78.3\%) showed a decline in FDG standardized uptake values (SUV) from baseline in all target lesions (range $-3 \%$ to $-74 \%$ ). All 16 evaluable patients treated at the MTD demonstrated a decrease in $\mathrm{SUV}_{\max }$ values during treatment; mean decrease was $25.8 \%$ (Supplementary Fig. S2). A weak negative correlation was observed between changes in FDG SUV $\mathrm{Sax}_{\text {max }}$ and drug exposure $\left(\mathrm{AUC}_{(0-25)}, R^{2}=0.1828\right.$; AUC from time 0 to the last data point, $R^{2}=0.2158$ ) (Supplementary Fig. S3).

\subsubsection{Biomarkers}

All 22 patients treated at the MTD had mutation data available for $\geq 1$ gene of interest and had a mutation in $\geq 1$ of the four genes assessed (Table 7). Tumor mutations were observed in $19 / 21$ patients $(90.5 \%)$ for $K R A S, 7 / 18(38.9 \%)$ for $P I 3 K C A$, and $1 / 19$ (5.3\%) for $B R A F$. No patients evaluated for NRAS harbored an NRAS tumor mutation. PIK3CA mutational status did not clearly associate with best response (stable disease rates were 3/6 [50\%] and 3/9 [33\%] for mutant and wild-type $P I K 3 C A$, respectively; $p=0.622$ ) or progression-free survival (PFS) (Supplementary Fig. S4A).

All patients with next-generation sequencing data $(n=13)$ had 5-29 tumor genetic mutations, most commonly (besides $K R A S)$ in TP53 $(10 / 13,76.9 \%)$ and $A P C(7 / 13,53.8 \%$; all CRC) (Supplementary Fig. S5).

Nineteen of 22 patients treated at the MTD had immunohistochemistry data for pretreatment PTEN, pAKT, pERK, and Ki-67. Four patients $(21.1 \%)$ had complete tumor PTEN protein loss, including three $(75.0 \%)$ with stable disease as best response, including the individual patient with the greatest tumor shrinkage (-28\%; Fig. 2). Three of 11 patients $(27 \%)$ with detectable PTEN had stable disease as best response. Patients with PTEN loss also showed a trend towards longer PFS (Supplementary Fig. S4B). The sole patient with DNA-level PTEN loss had stable disease as best response, but had insufficient tumor sample for PTEN immunohistochemistry. Patients with high (above median) pretreatment pERK levels had shorter PFS than those with low pERK (Supplementary Fig. S4C). A relationship between high baseline Ki-67 and shorter PFS was observed (analyzed as a continuous variable, $p=0.027$; hazard ratio 1.012; suggesting that the risk of progression increases by $1.2 \%$ for every 1-point increase in $\mathrm{Ki}-67 \mathrm{H}$-score), and Ki-67 dichotomization showed a similar trend (Supplementary Fig. S4D).

Five patients in the expansion cohort had evaluable paired tumor biopsies collected before and during treatment; all demonstrated a reduction in pERK levels during treatment versus baseline, three had reduced pAKT levels, and four had reduced Ki-67 levels (Supplementary Fig. S6). Stronger inhibition of pERK, pAKT, and/or Ki-67 did not clearly correspond with improved response, as the two patients with the greatest total decreases in pERK, pAKT, and Ki-67 tumor levels had progressive disease as best response.

\section{Discussion}

This phase Ib study evaluated the safety, tolerability, and RP2D of intravenous copanlisib (intermittent dosing, weekly or 3 weeks on/1 week off) combined with oral refametinib (continuous or intermittent dosing) in patients with advanced cancer. The MTD for the combination was determined as copanlisib $0.4 \mathrm{mg} / \mathrm{kg}$ weekly and refametinib $30 \mathrm{mg}$ BID, doses lower than for the individual drugs as monotherapy (0.8 $\mathrm{mg} / \mathrm{kg}$ and $50 \mathrm{mg}$, respectively) [7, 11]. DLTs included class-effect toxicities associated with PI3K inhibitors (e.g., diarrhea [8, 17]) and MEK inhibitors (e.g., rash [18, 19]), and toxicities previously reported with dual inhibition of 


\begin{tabular}{|c|c|}
\hline & $\begin{array}{l}\text { Pancreatic } \\
\text { Cervical } \\
\text { Kidney } \\
\text { Colorectal } \\
\text { Colorectal } \\
\text { Pancreatic }\end{array}$ \\
\hline & $\begin{array}{l}\text { Colorectal } \\
\text { NSCLC } \\
\text { Colorectal } \\
\text { Ovarian } \\
\text { Unknown } \\
\text { Gastric }\end{array}$ \\
\hline & $\begin{array}{l}\text { NSCLC } \\
\text { Thymus } \\
\text { Breast } \\
\text { Breast } \\
\text { Breast } \\
\text { Mesotheliom } \\
\text { Pancreatic } \\
\text { Ovarian } \\
\text { Ovarian } \\
\text { NSCLC }\end{array}$ \\
\hline & $\begin{array}{l}\text { Uterine }^{c} \\
\text { Lung }^{d} \\
\text { Vulva } \\
\text { Colorectal } \\
\text { Apocrine } \\
\text { Breast }\end{array}$ \\
\hline & $\begin{array}{l}\text { NSCLC } \\
\text { Hepatobiliary } \\
\text { Colorectal } \\
\text { Colorectal } \\
\text { Intracraniale } \\
\text { Gastric }\end{array}$ \\
\hline
\end{tabular}

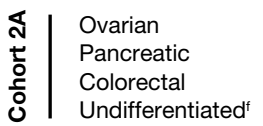

พี Ovarian

ㄴ. NSCLC

¿

Pancreatic

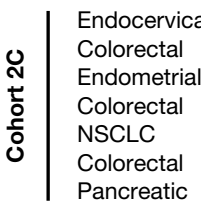

NSCLC

NSCLC

Colorectal

Colorectal

Bladder

Ovarian

Colorectal

Colorectal

Colorectal

Colorectal

Colorectal

Colorectal

Colorectal

Colorectal

Colorectal

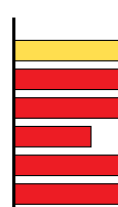

\section{Best response}

$\square$ Stable disease

$\square$ Non-complete response/ non-progressive disease ${ }^{a}$

$\square$ Disease progression

$\square$ Not evaluable
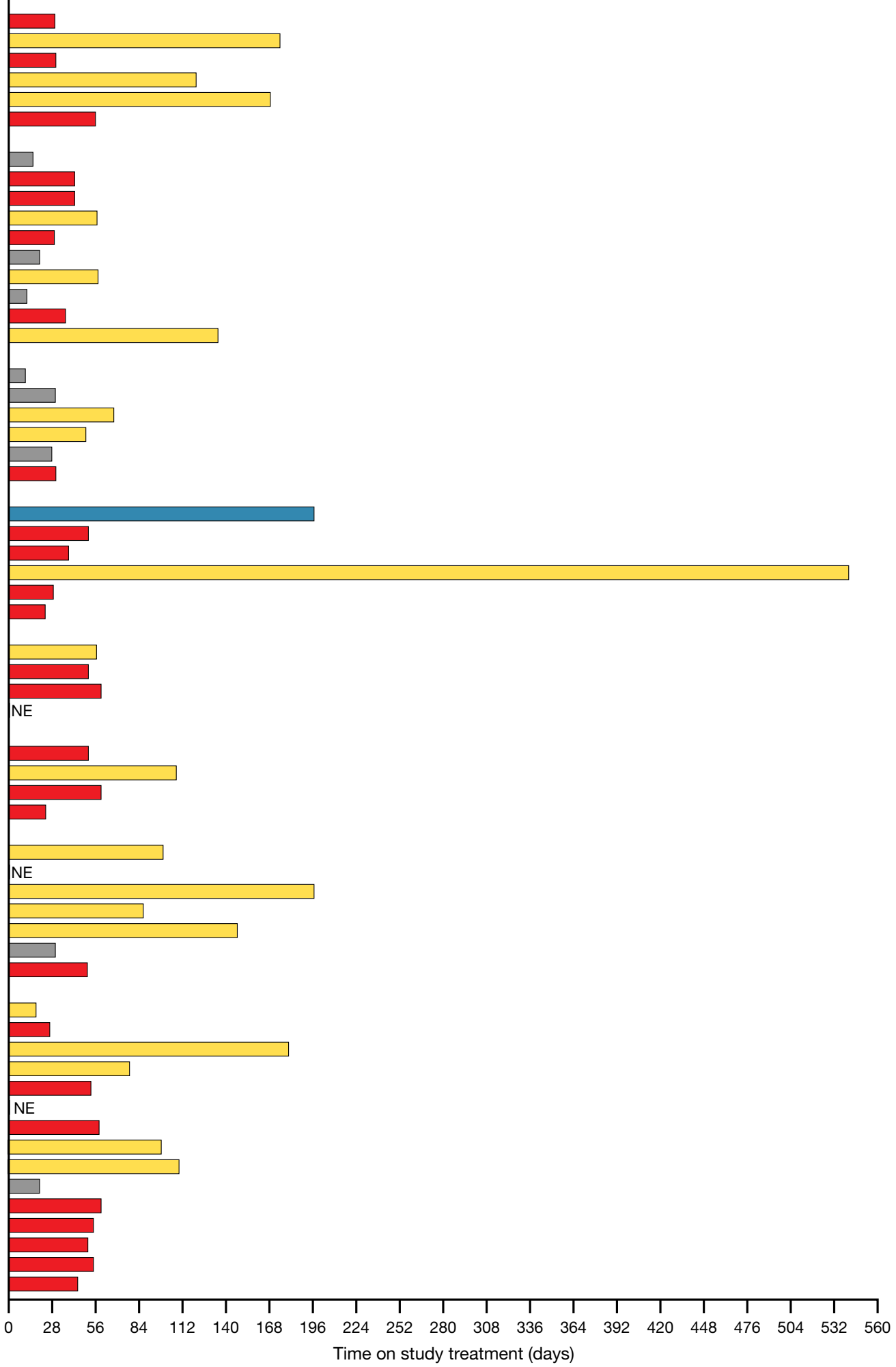
4Fig. 1 Time on study treatment by cohort and by RECIST best response; 28 days $=1$ cycle. ${ }^{\text {a}}$ Response only valid for non-target lesions. ${ }^{\mathrm{b}}$ Eleven patients had missing imaging for post-baseline RECIST assessment and were classified as not evaluable. 'Leiomyosarcoma. ${ }^{\mathrm{d}}$ Neuroendocrine tumor. ${ }^{\mathrm{e}}$ Hemangiopericytoma. ${ }^{\mathrm{f}} \mathrm{Sar}-$ coma. NE not evaluable, NSCLC non-small-cell lung cancer, RECIST Response Evaluation Criteria in Solid Tumors version 1.1

the PI3K/AKT/mTOR and RAS/RAF/MAPK pathways [20]. Based on TEAEs leading to discontinuation at the MTD, short treatment duration (6-7 weeks), and lack of objective responses, an RP2D and schedule that were both tolerable and offered clear efficacy in the population assessed could not be identified for this drug combination.

The most common TEAEs ( $>50 \%$ incidence) included gastrointestinal toxicities, dermatologic toxicities, and fatigue, consistent with those observed in monotherapy studies of refametinib [11] and copanlisib [21]. The incidence of dermatologic toxicities was consistent with reports of other MEK inhibitors [18, 19, 22]. Rash TEAEs were generally mild (grade 1 or 2); although infrequent, rash was among the most common grade 3 TEAEs leading to discontinuation. Hyperglycemia (all-grade, 40.6\%) is an ontarget effect of PI3K inhibitors and was treatment-related and reversible, similar to copanlisib monotherapy reports $[8,21,23]$. The incidence of hypertension (all-grade, $39.1 \%$ ) was also consistent with reports of copanlisib monotherapy $[7,8,21]$. Increased creatine phosphokinase was the most common grade 4 TEAE $(3.1 \%)$, consistent with reports of
PI3K and MEK inhibitor combination therapies [15, 24-26]. High rates of ophthalmologic toxicities have been associated with some MEK inhibitors (e.g., 19\% incidence [all-cause] with trametinib and $27 \%$ incidence with RO4987655) [27], although were infrequent here (all-grade, 12.5\%) and mostly mild in severity [18].

Pharmacokinetic characteristics for copanlisib combined with refametinib were consistent with those reported for copanlisib monotherapy [7]. Copanlisib exposure $\left(C_{\max }\right.$ and $\mathrm{AUC}_{(0-25)}$ ) was comparable between day 1 (copanlisib alone) and day 15 (copanlisib and refametinib), suggesting that co-administration with refametinib did not influence copanlisib pharmacokinetics. Pharmacokinetic characteristics for refametinib in combination generally reflected those for refametinib monotherapy [11]; however, refametinib exposure $\left(C_{\max }\right.$ and $\left.\mathrm{AUC}_{(0-8)}\right)$ was slightly reduced with concomitant copanlisib. No clinically relevant pharmacokinetic interactions between copanlisib and refametinib were observed.

No objective responses were observed, consistent with the inadequate efficacy reported from studies with other PI3K and MEK inhibitor combinations [25, 26, 28-30]. This was unexpected based on preclinical evidence of such combinations being synergistic [3, 4]. Furthermore, in combination with gemcitabine, the current standard-of-care therapy for many advanced cancers, copanlisib and refametinib have demonstrated promising clinical responses in patients with advanced cancer $[31,32]$. In this study, the response rate was

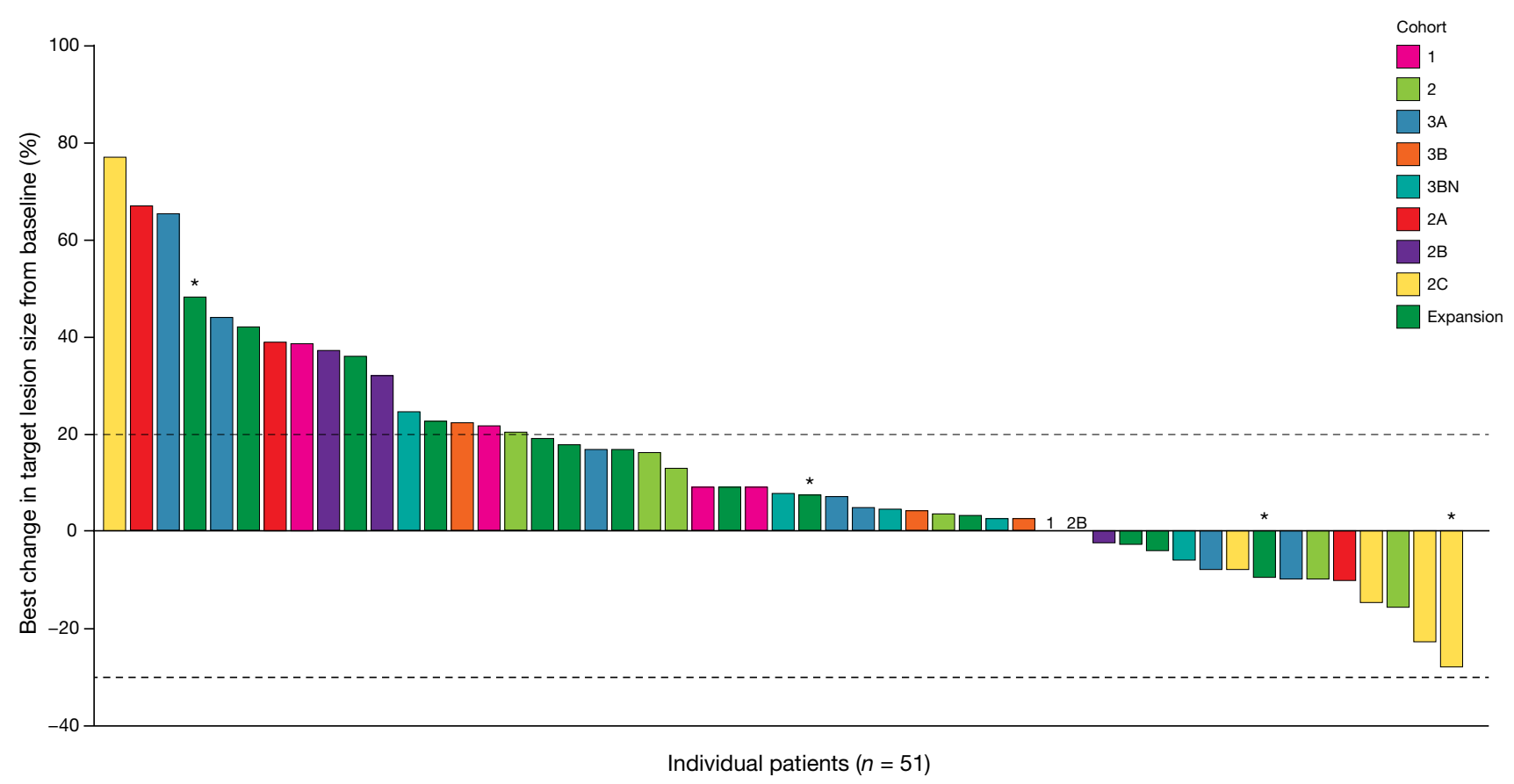

Fig. 2 Best change in target lesion size from baseline by cohort. Each bar represents one patient; the best change in target lesion size per investigator assessment could not be determined in 13 patients. "Asterisk" - patients with PTEN loss 
Table 7 Tumor mutations in cohort $2 \mathrm{C}$ and the expansion cohort $(n=22)$

\begin{tabular}{|c|c|c|c|c|}
\hline Cohort/tumor type & Gene & Historic $^{\mathrm{a}}$ & $\operatorname{ctDNA}^{\mathrm{b}}$ & $\mathrm{NGS}^{\mathrm{b}}$ \\
\hline Expansion/bladder & $P I K 3 C A$ & E545K & E545K & - \\
\hline Cohort 2C/cervical & $K R A S$ & A146V & - & - \\
\hline Cohort $2 \mathrm{C} /$ colorectal & $K R A S$ & G12A & - & G12A \\
\hline Cohort $2 \mathrm{C} /$ colorectal & $K R A S$ & G12A & - & - \\
\hline Cohort $2 \mathrm{C} /$ colorectal & $K R A S$ & - & - & $\mathrm{CN}: 17$ \\
\hline Expansion/colorectal & $K R A S$ & G13D & G13D & G13D \\
\hline Expansion/colorectal & $K R A S$ & G12V & G12V & - \\
\hline Expansion/colorectal & $K R A S$ & G12D & G12D & G12D \\
\hline Expansion/colorectal & $K R A S$ & G12A & G12A & - \\
\hline Expansion/colorectal & $K R A S$ & G12D & G12D & G12D \\
\hline Expansion/colorectal & $K R A S$ & G13D & WT & G13D \\
\hline Expansion/colorectal & $K R A S$ & G12D & WT & WT \\
\hline \multirow[t]{2}{*}{ Expansion/colorectal } & $K R A S$ & G12V & G12V & - \\
\hline & $P I K 3 C A$ & - & E542K & - \\
\hline \multirow[t]{2}{*}{ Expansion/colorectal } & $K R A S$ & G13D & G13D & G13D \\
\hline & $P I K 3 C A$ & - & $\mathrm{WT}^{\mathrm{c}}$ & $\mathrm{CN}: 28$ \\
\hline \multirow[t]{2}{*}{ Expansion/colorectal } & $K R A S$ & G12D & G12D & G12D \\
\hline & $P I K 3 C A$ & E542K & E542K & E542K \\
\hline \multirow[t]{2}{*}{ Expansion/colorectal } & $K R A S$ & G12S & G12S & G12S \\
\hline & $P I K 3 C A$ & - & E545K & WT \\
\hline Cohort 2C/endometrial & $P I K 3 C A$ & - & - & N1044K \\
\hline Cohort 2C/NSCLC & $K R A S$ & G12C & - & - \\
\hline Expansion/NSCLC & $K R A S$ & $\mathrm{G} 12 \mathrm{C}$ & WT & - \\
\hline \multirow[t]{2}{*}{ Expansion/NSCLC } & $K R A S$ & G12R & G12R & G12R \\
\hline & $P I K 3 C A$ & - & E545K & WT \\
\hline Expansion/ovarian & $B R A F$ & $\begin{array}{l}\text { Complex } \\
\text { rearrange- } \\
\text { ment }\end{array}$ & - & - \\
\hline Cohort $2 \mathrm{C} /$ pancreatic & $K R A S$ & - & - & G12D \\
\hline
\end{tabular}

$C N$ copy number, $c t D N A$ circulating tumor DNA, NGS next-generation sequencing, NSCLC non-small-cell lung cancer, $W T$ wild-type, — not tested/not available

${ }^{a}$ Any tumor mutation result generated before enrollment into the trial

${ }^{\mathrm{b}}$ Test performed centrally

${ }^{c}$ ctDNA test cannot detect copy number alterations

similar to that observed in the phase I study of refametinib monotherapy (partial response rate $0 \%$ vs. $2 \%$, respectively), although stable disease was more frequent here $(32.8 \%$ vs. $16 \%$ ) [11]. The lack of objective responses observed here, despite enrichment for tumor types with RAS-MAPK or PI3K signaling pathway mutations in the expansion cohort, may be partially explained by the MTD of the combination being lower than that of the individual compounds as monotherapy $[7,11]$. This is consistent with a recent pharmacodynamic study showing that copanlisib $0.4 \mathrm{mg} / \mathrm{kg}$ as monotherapy was less active than $0.8 \mathrm{mg} / \mathrm{kg}$ [33]. Further, median duration of treatment was short due to toxicities, likely resulting in insufficient exposure.
Patients with complete tumor PTEN loss showed a trend towards better outcomes, suggesting these patients may be more responsive to treatment, whereas patients with high baseline pERK, pAKT, and Ki-67 levels showed a trend towards shorter PFS, possibly indicative of a poorer prognosis. Some indicators of a pharmacodynamic effect were seen in patients with relevant evidence of tumorigenic activity (decreases in FDG-PET signal and tumor pERK levels). The limited number of patients with relevant gene mutations might contribute to the lack of observed response; favorable objective response rates have been observed in studies of MEK inhibitors in monotherapy or combined with PI3K inhibitors in patients with $R A S$ - and/or $B R A F$-mutant solid tumors $[15,34]$. Optimal dosing for PI3K-MEK inhibitor combinations remains to be confirmed.

In conclusion, despite the scientific rationale for combining PI3K and MEK inhibitors, the copanlisib plus refametinib combination was not tolerated at doses expected to be clinically active. Further development of the combination is not warranted.

Acknowledgements We thank Andrea Kelly and Chenghua Xia for their support in this study.

Author Contributions RKR, DDVH, IG, SR, CG, and CP contributed to the conception and the design of the study; RKR, DDVH, FE, $\mathrm{GB}$, DR, and KM contributed to the acquisition of data; all authors contributed to the analysis and interpretation of the data; AS and CP contributed to the statistical analysis; all authors contributed to the preparation, editing, and review of the manuscript.

Funding This study was supported by Bayer AG. Bayer had a role in the study design, data analysis, data interpretation, writing of the report, and in the decision to submit the paper for publication. Bayer had no role in data collection.

\section{Compliance with Ethical Standards}

Conflict of Interest R. K. Ramanathan is currently employed by Merck and received research funding from Bayer for the conduct of the study. D.D. Von Hoff is employed as a consultant at McKesson; reports stock and ownership at Anthem, Inc., CerRx, Medtronic, Stromatis Pharma, SynDevRx, Systems Oncology, and UnitedHealthcare; has participated in a consulting or advisory role for Aadi, Actinium Pharmaceuticals, Adicet Bio, Aeglea BioTherapeutics, Agenus, AiMed Bio, Alpha Cancer Technologies, Amunix, APEIRON, Aptose Biosciences, Arvinas, Athenex, Bellicum Pharmaceuticals, BioLineRx, BioSpecifics Technologies, BioXCel Therapeutics, Boston Scientific, Bryologyx, CanBas, Celgene, Codiak Biosciences, Corcept Therapeutics, CORRONA, CV6 Therapeutics, CytomX Therapeutics, Decoy Biosystems, DNAtrix, EMD Serono, Erimos Pharmaceuticals, Esperance Pharmaceuticals, Evelo Biosciences, Fate Therapeutics, FibroGen, Five Prime Therapeutics, Fujifilm, Geistlich Pharma, Genzada Pharmaceuticals, Gimbal, GiraFpharma, Globe Life Sciences, Helix BioPharma, Hills Pharma, Histogen, Horizon Discovery, HUYA Bioscience International, Imaging Endpoints, Immodulon Therapeutics, Immunophotonics, Innokeys, Intezyne Technologies, Ipsen, Jounce Therapeutics, Kalos Therapeutics, Kelun-Klus Pharma, Kura, L.E.A.F. Pharmaceuticals, Lixte Biotechnology, Medical Prognosis Institute, Novita Pharmaceuticals, Novocure, NuCana BioMed, Oncology Venture, Oncolyze, Pfiz- 
er, Phosplatin Therapeutics, Radimmune, RefleXion Medical, RenovoRx, Riptide Bioscience, Samumed, Samus Therapeutics, Senhwa Biosciences, Sirnaomics, Sobi, SOTIO, Strategia Therapeutics, Sun Biopharma, Synergene, TD2, Tolero Pharmaceuticals, TP Therapeutics, TransMed, Trovagene, Verily, Vicus Therapeutics, and 2X Oncology; and has received research funding from AbbVie, Aduro Biotech, Agios, ArQule, Baxalta, Celgene, Cleave Biosciences, CytRx Corporation, Daiichi Sankyo, Deciphera, Endocyte, ESSA, Exelixis, Five Prime Therapeutics, Genentech, Gilead Sciences, Halozyme, Incyte, Lilly, Merck, Merrimack, Minneamrita Therapeutics, Mirna Therapeutics, Pfizer, Pharmacyclics, Phoenix Biotech, Plexxikon, Proderm IQ, Samumed, Strategia, Trovagene, Verastem, and 3-V Biosciences. G. Blumenschein Jr has received grants from Adaptimmune, AstraZeneca, Bayer, Bristol-Myers Squibb, Celgene, Exelixis, Genentech, GlaxoSmithKline, Immatics, Immunocore, Incyte, Kite Pharma, MacroGenics, MedImmune, Merck, Novartis, Roche, Tmunity, Torque, and Xcovery; and has received personal fees from AbbVie, Adicet, Amgen, ARIAD, AstraZeneca, Bayer, Bristol-Myers Squibb, Celgene, Clovis, Genentech, Johnson \& Johnson, Maverick Therapeutics, MedImmune, Merck, Novartis, Roche, Virogin Biotech, and Xcovery. I. Genvresse is employed by Bayer AG. C. Granvil is employed by Bayer HealthCare Pharmaceuticals, Inc. A. Skubala is employed by Chrestos Concept GmbH \& Co. KG and acts as a consultant to Bayer. C. Peña is employed by and owns stock at Bayer HealthCare Pharmaceuticals, Inc., and is a co-inventor on Bayer patents related to one of the investigational drugs used in the present study. K. Mross has received grants and support for travel from Bayer AG. F. Eskens, D. Richards, and S. Reschke report no conflicts of interest.

Medical Writing Assistance We thank Jack Adams, MSc, of Complete HealthVizion for providing medical writing assistance with the manuscript, based on detailed discussion and feedback from all authors. This assistance was funded by Bayer AG.

Informed Consent The study was compliant with the Declaration of Helsinki and Good Clinical Practice, and was approved by the appropriate ethics committees. All patients provided written, informed consent.

Open Access This article is licensed under a Creative Commons Attribution-NonCommercial 4.0 International License, which permits any non-commercial use, sharing, adaptation, distribution and reproduction in any medium or format, as long as you give appropriate credit to the original author(s) and the source, provide a link to the Creative Commons licence, and indicate if changes were made. The images or other third party material in this article are included in the article's Creative Commons licence, unless indicated otherwise in a credit line to the material. If material is not included in the article's Creative Commons licence and your intended use is not permitted by statutory regulation or exceeds the permitted use, you will need to obtain permission directly from the copyright holder. To view a copy of this licence, visit http://creativecommons.org/licenses/by-nc/4.0/.

\section{References}

1. Shimizu T, Tolcher AW, Papadopoulos KP, Beeram M, Rasco DW, Smith LS, et al. The clinical effect of the dual-targeting strategy involving PI3K/AKT/mTOR and RAS/MEK/ERK pathways in patients with advanced cancer. Clin Cancer Res. 2012;18:2316-25.

2. Serra V, Scaltriti M, Prudkin L, Eichhorn PJA, Ibrahim YH, Chandarlapaty S, et al. PI3K inhibition results in enhanced HER signaling and acquired ERK dependency in HER2-overexpressing breast cancer. Oncogene. 2011;30:2547-57.

3. Haagensen EJ, Kyle S, Beale GS, Maxwell RJ, Newell DR. The synergistic interaction of MEK and PI3K inhibitors is modulated by mTOR inhibition. Br J Cancer. 2012;106:1386-94.

4. Roberts PJ, Usary JE, Darr DB, Dillon PM, Pfefferle AD, Whittle MC, et al. Combined PI3K/mTOR and MEK inhibition provides broad antitumor activity in faithful murine cancer models. Clin Cancer Res. 2012;18:5290-303.

5. Liu N, Rowley BR, Bull CO, Schneider C, Haegebarth A, Schatz CA, et al. BAY 80-6946 is a highly selective intravenous PI3K inhibitor with potent $\mathrm{p} 110 \alpha$ and $\mathrm{p} 110 \delta$ activities in tumor cell lines and xenograft models. Mol Cancer Ther. 2013;12:2319-30.

6. Scott WJ, Hentemann MF, Rowley RB, Bull CO, Jenkins S, Bullion AM, et al. Discovery and SAR of novel 2,3-dihydroimidazo[1,2-c]quinazoline PI3K inhibitors: identification of copanlisib (BAY 80-6946). ChemMedChem. 2016;11:1517-30.

7. Patnaik A, Appleman LJ, Tolcher AW, Papadopoulos KP, Beeram M, Rasco DW, et al. First-in-human phase I study of copanlisib (BAY 80-6946), an intravenous pan-class I phosphatidylinositol 3-kinase inhibitor, in patients with advanced solid tumors and non-Hodgkin's lymphomas. Ann Oncol. 2016;27:1928-40.

8. Dreyling M, Santoro A, Mollica L, Leppä S, Follows GA, Lenz G, et al. Phosphatidylinositol 3-kinase inhibition by copanlisib in relapsed or refractory indolent lymphoma. J Clin Oncol. 2017;35:3898-905.

9. US Food and Drug Administration. ALIQOPA (copanlisib) highlights of prescribing information. https://www.accessdata.fda.gov/ drugsatfda_docs/label/2017/209936s0001bl.pdf. Accessed 9 Sep 2019.

10. Iverson C, Larson G, Lai C, Yeh LT, Dadson C, Weingarten P, et al. RDEA119/BAY 869766: a potent, selective, allosteric inhibitor of MEK1/2 for the treatment of cancer. Cancer Res. 2009;69:6839-47.

11. Weekes CD, Von Hoff DD, Adjei AA, Leffingwell DP, Eckhardt SG, Gore L, et al. Multicenter phase I trial of the mitogen-activated protein kinase 1/2 inhibitor BAY 86-9766 in patients with advanced cancer. Clin Cancer Res. 2013;19:1232-43.

12. Liu N, Puehler F, Haegebarth A, Scholz A, Hoffmann J, Dubowy RL, et al. Combination of PI3K inhibitor BAY 80-6946 and allosteric MEK inhibitor BAY 86-9766 (RDEA119) is a promising approach for the treatment of colorectal cancers. Poster 151 presented at the 22nd EORTC-NCI-AACR Symposium, Berlin, Germany, 16-19 November 2010.

13. Liu N, Puehler F, Haegebarth A, Scholz A, Hoffman J, Mumberg D, et al. Combination of PI3K inhibitor BAY 80-6946 with allosteric MEK inhibitor BAY 86-9766 (RDEA119) and with erlotinib for the treatment of non-small-cell lung cancer. Poster 097 presented at the 22nd EORTC-NCI-AACR Symposium, Berlin, Germany, 16-19 November 2010.

14. Haegebarth A, Haike K, Paul J, Mumberg D, Ziegelbauer K, Liu N. Potent in vitro and in vivo anti-tumor activity of PI3K inhibitor BAY 80-6946 and MEK inhibitor BAY 86-9766 in preclinical biliary tract cancer models. Poster 869 presented at the 103rd Annual Meeting of the American Association for Cancer Research, Chicago, IL, USA, March 31-April 4, 2012.

15. Bedard PL, Tabernero J, Janku F, Wainberg ZA, Paz-Ares L, Vansteenkiste J, et al. A Phase Ib dose-escalation study of the oral pan-PI3K inhibitor buparlisib (BKM120) in combination with the oral MEK1/2 inhibitor trametinib (GSK1120212) in patients with selected advanced solid tumors. Clin Cancer Res. 2015;21:730-8.

16. Schram AM, Gandhi L, Mita MM, Damstrup L, Campana F, Hidalgo M, et al. A phase Ib dose-escalation and expansion study of the oral MEK inhibitor pimasertib and PI3K/MTOR inhibitor 
voxtalisib in patients with advanced solid tumours. Br J Cancer. 2018;119:1471-6.

17. Gopal AK, Kahl BS, de Vos S, Wagner-Johnston ND, Schuster SJ, Jurczak WJ, et al. PI3K $\delta$ inhibition by idelalisib in patients with relapsed indolent lymphoma. N Engl J Med. 2014;370:1008-18.

18. Bendell JC, Javle M, Bekaii-Saab TS, Finn RS, Wainberg ZA, Laheru DA, et al. A phase 1 dose-escalation and expansion study of binimetinib (MEK162), a potent and selective oral MEK1/2 inhibitor. Br J Cancer. 2017;116:575-83.

19. Falchook GS, Lewis KD, Infante JR, Gordon MS, Vogelzang NJ, DeMarini DJ, et al. Activity of the oral MEK inhibitor trametinib in patients with advanced melanoma: a phase 1 dose-escalation trial. Lancet Oncol. 2012;13:782-9.

20. Tolcher AW, Bendell JC, Papadopoulos KP, Burris HA, Patnaik A, Jones SF, et al. A phase IB trial of the oral MEK inhibitor trametinib (GSK1120212) in combination with everolimus in patients with advanced solid tumors. Ann Oncol. 2015;26:58-64.

21. Dreyling M, Morschhauser F, Bouabdallah K, Bron D, Cunningham D, Assouline SE, et al. Phase II study of copanlisib, a PI3K inhibitor, in relapsed or refractory, indolent or aggressive lymphoma. Ann Oncol. 2017;28:2169-78.

22. Leijen S, Middleton MR, Tresca P, Kraeber-Bodéré F, Dieras V, Scheulen ME, et al. Phase I dose-escalation study of the safety, pharmacokinetics, and pharmacodynamics of the MEK inhibitor RO4987655 (CH4987655) in patients with advanced solid tumors. Clin Cancer Res. 2012;18:4794-805.

23. Morschhauser F, Machiels J-P, Salles G, Rottey S, Rule SAJ, Cunningham $\mathrm{D}$, et al. On-target pharmacodynamic activity of the PI3K inhibitor copanlisib in paired biopsies from patients with malignant lymphoma and advanced solid tumors. Mol Cancer Ther. 2020;19:468-78.

24. Britten CD. PI3K and MEK inhibitor combinations: examining the evidence in selected tumor types. Cancer Chemother Pharmacol. 2013;71:1395-409.

25. Wainberg ZA, Alsina M, Soares HP, Brana I, Britten CD, Del Conte G, et al. A multi-arm Phase I study of the PI3K/mTOR inhibitors PF-04691502 and gedatolisib (PF-05212384) plus irinotecan or the MEK inhibitor PD-0325901 in advanced cancer. Target Oncol. 2017;12:775-85.
26. Mita M, Fu S, Piha-Paul SA, Janku F, Mita A, Natale R, et al. Phase I trial of MEK 1/2 inhibitor pimasertib combined with mTOR inhibitor temsirolimus in patients with advanced solid tumors. Invest New Drugs. 2017;35:616-26.

27. Stjepanovic N, Velazquez-Martin JP, Bedard PL. Ocular toxicities of MEK inhibitors and other targeted therapies. Ann Oncol. 2016;27:998-1005.

28. Do K, Speranza G, Bishop R, Khin S, Rubinstein L, Kinders RJ, et al. Biomarker-driven phase 2 study of MK-2206 and selumetinib (AZD6244, ARRY-142886) in patients with colorectal cancer. Invest New Drugs. 2015;33:720-8.

29. Grilley-Olson JE, Bedard PL, Fasolo A, Cornfeld M, Cartee L, Razak AR, et al. A phase Ib dose-escalation study of the MEK inhibitor trametinib in combination with the PI3K/mTOR inhibitor GSK2126458 in patients with advanced solid tumors. Invest New Drugs. 2016;34:740-9.

30. Shapiro GI, LoRusso P, Kwak E, Pandya S, Rudin CM, Kurkjian $\mathrm{C}$, et al. Phase Ib study of the MEK inhibitor cobimetinib (GDC0973) in combination with the PI3K inhibitor pictilisib (GDC0941) in patients with advanced solid tumors. Invest New Drugs. 2020;38:419-32.

31. Kim RD, Alberts SR, Pena C, Genvresse I, Ajavon-Hartmann A, $\mathrm{Xia}$ C, et al. Phase I dose-escalation study of copanlisib in combination with gemcitabine or cisplatin plus gemcitabine in patients with advanced cancer. Br J Cancer. 2018;118:462-70.

32. Van Laethem JL, Riess H, Jassem J, Haas M, Martens UM, Weekes C, et al. Phase I/II study of refametinib (BAY 86-9766) in combination with gemcitabine in advanced pancreatic cancer. Target Oncol. 2017;12:97-109.

33. Morschhauser F, Machiels JP, Salles G, Rottey S, Rule SAJ, Cunningham D, et al. On-target pharmacodynamic activity of the PI3K inhibitor copanlisib in paired biopsies from patients with malignant lymphoma and advanced solid tumors. Mol Cancer Ther. 2020;19:468-78.

34. Farley J, Brady WE, Vathipadiekal V, Lankes HA, Coleman R, Morgan MA, et al. Selumetinib in women with recurrent lowgrade serous carcinoma of the ovary or peritoneum: an open-label, single-arm, phase 2 study. Lancet Oncol. 2013;14:134-40.

\section{Affiliations}

\section{Ramesh K. Ramanathan ${ }^{1}$ - Daniel D. Von Hoff ${ }^{1}$. Ferry Eskens ${ }^{2}$. George Blumenschein $\mathrm{Jr}^{3}{ }^{3}$. Donald Richards ${ }^{4}$. Isabelle Genvresse ${ }^{5}$. Susanne Reschke ${ }^{5} \cdot$ Camille Granvil $^{6} \cdot$ Adam Skubala $^{7} \cdot$ Carol Peña $^{6} \cdot$ Klaus Mross $^{8}$}

1 Virginia G. Piper Cancer Center/TGen, Scottsdale, AZ 85004, USA

2 Erasmus MC Cancer Institute, PO Box 2040, 3015 GD Rotterdam, The Netherlands

3 The University of Texas MD Anderson Cancer Center, Unit 432, PO Box 301402, Houston, TX 77030, USA

4 US Oncology Research, Texas Oncology, 910 E. Houston St., Suite 100, Tyler, TX 75702, USA
5 Pharmaceutical Division, Bayer AG, Müllerstraße 178, 13353 Berlin, Germany

6 Bayer HealthCare Pharmaceuticals, Inc., 100 Bayer Blvd, Whippany, NJ 07981, USA

7 Chrestos Concept GmbH \& Co. KG, Girardetstr. 1-5, 45131 Essen, Germany

8 KTB Klinik für Tumorbiologie, Breisacher Str. 117, 79106 Freiburg im Breisgau, Baden-Württemberg, Germany 